\title{
Juvenile polyposis in a tropical country
}

\author{
Ujjal Poddar, B R Thapa, K Vaiphei, K L N Rao, S K Mitra, Kartar Singh
}

\begin{abstract}
The clinical profile, malignant potential, and management of 17 children with juvenile polyposis (more than five juvenile polyps) were evaluated clinically and endoscopically. Colonoscopy and polypectomy were done three weekly until colonic clearance was achieved, and thereafter two yearly. All polyps were subjected to histological examination. Mean age was 7.7 years, with a male preponderance (3:1). Presentation was with rectal bleeding $(94 \%)$, pallor $(65 \%)$, stunted growth $(53 \%)$, and oedema (47\%), and the mean (SD) duration of symptoms was 33 (27) months. None had a positive family history or any congenital anomaly. Two children had six polyps up to the transverse colon; the rest had numerous polyps all over the colon. All children had juvenile polyps on histology and 10 (59\%) had adenomatous changes (dysplasia). Total colectomy was done in six for intractable symptoms. Colon clearance was achieved in eight after an average 3.4 polypectomy sessions, and three were still on the polypectomy programme. In conclusion, juvenile polyposis is commonly associated with low grade dysplasia. Serial colonoscopic polypectomy is effective but colectomy is required for intractable symptoms and when clearance of the colon is not possible.

(Arch Dis Child 1998;78:264-266)
\end{abstract}

Keywords: juvenile polyposis; colectomy; dysplasia

Polyps occur in as many as $1 \%$ of children, and $90 \%$ of colonic polyps in children are "juvenile" as defined histologically. ${ }^{1}$ Juvenile polyps are generally thought to be hamartomatous lesions with little malignant potential. "Juvenile polyposis coli," on the other hand, is a rare condition with neoplastic potential; it is, however, better to label this condition "juvenile polyposis," as polyps can also be seen in other parts of the gastrointestinal tract. ${ }^{2}$ McColl et al first described the syndrome of juvenile polyposis in $1964,{ }^{2}$ and by 1966 had established its familial nature in some cases. ${ }^{3}$ In 1970, Sachatello et al described a related syndrome of generalised polyposis. ${ }^{4}$

There is controversy over the definition of juvenile polyposis. While some investigators ${ }^{5}$ have suggested that as few as three juvenile polyps are sufficient for a diagnosis of juvenile polyposis, others ${ }^{6}$ have taken more than 10 colonic juvenile polyps as the criterion for diagnosis. The most widely accepted definition, by Jass et $a l^{7}{ }^{7}$ requires any one of the following: (1) more than five juvenile polyps of the colorectum; (2) juvenile polyps throughout the gastrointestinal tract; (3) any number of juvenile polyps with a family history of juvenile polyposis.

Juvenile polyposis is an uncommon condition, and most reports have been in the form of anecdotal case studies. ${ }^{5-9}$ There have been no reports from Asia and no series in children. We now present a study of the clinical profile, malignant potential, and management of juvenile polyposis in Indian children ( $\leqslant 12$ years).

\section{Patients and methods}

We studied 17 children with juvenile polyposis (more than five juvenile polyps) admitted to the paediatric gastroenterology centre of our institute between March 1991 and October 1996. Their detailed history and clinical examination were recorded. Laboratory investigations including a full blood count, total serum protein, albumin, and barium enema were done. The children were then prepared for fibreoptic flexible colonoscopy, either as an inpatient or as a day case.

Initially we prepared the children with a liquid diet and a laxative (liquid paraffin) for two days and a saline enema one hour before the procedure. For the last two years, we have been using polyethylene glycol preparation on the day of the procedure. An injection of diazepam $(0.5 \mathrm{mg} / \mathrm{kg}$ intravenously) was used for sedation as required. General anaesthesia was not used in any patient.

Colonoscopy was done with a PCF or CFP1OI (Olympus) scope. Polyps seen on colonoscopy were removed by snare cautery. Patients were observed for six to 24 hours following polypectomy to detect any complication. Children with more than five polyps were labelled as juvenile polyposis ${ }^{7}$ and all underwent full length colonoscopy. All the children had oesophagogastroduodenoscopy and barium meal and follow through at least once. Serial colonoscopic polypectomies were done every three weeks until colonic clearance was achieved. Up to 10 polyps were removed in a single session.

Children were subjected to surgery (total colectomy) when: (1) there were intractable symptoms in the form of rectal bleeding, protein losing enteropathy, or stunted growth, despite repeated colonoscopic polypectomy, or (2) clearing of the polyps by colonoscopy was not possible. All the polyps removed by snare polypectomy and surgically resected specimens were subjected to histopathological examination by a single gastrointestinal pathologist. Associated dysplasia, if present, was graded according to World Health Organisation grading. ${ }^{10}$ Children were followed up with surveillance colonoscopy after their colons were 
Table 1 Clinical features of 17 children

\begin{tabular}{lcl}
\hline & No of children & Percentage \\
\hline Rectal bleeding & 16 & 94 \\
Pallor & 11 & 65 \\
Stunted growth & 9 & 53 \\
Oedema & 8 & 47 \\
Recurrent intussusception & 2 & 12 \\
Diarrhoea & 1 & 6 \\
Family history of juvenile & 0 & 0 \\
polyposis & & 0 \\
Associated congenital defects & 0 & 0 \\
\hline
\end{tabular}

Table 2 Number and distribution of polyps

\begin{tabular}{llc}
\hline Site of polyps & No of polyps & No of children \\
\hline Up to transverse colon & 6 & 2 \\
All over the colon & Numerous & 15 \\
Polyps in the stomach & 2 & 1 \\
Terminal ileum & Multiple & 1 \\
\hline
\end{tabular}

cleared of polyps, either two yearly or whenever symptomatic, whichever was earlier.

\section{Results}

During the study period, 353 children underwent colonoscopy and 208 (59\%) of them had colonic polyps. Juvenile polyposis was diagnosed in 17 children ( $8 \%$ ). Their age ranged from 3 to 12 years, with a mean of 7.7 years. The male to female ratio was $3: 1$. Their presentation is summarised in table 1 . Mean (SD) duration of symptoms was 33 (27) months (range four to 96 months). One child started having symptoms at 18 months of age (infantile type) in the form of diarrhoea, rectal bleeding, oedema, and anaemia requiring blood transfusions. Two children presented with recurrent intussusception. Twelve had anaemia and eight had associated hypoproteinaemia. None of our children had associated congenital defects or a family history of juvenile polyposis or colon carcinoma.

The number and distribution of polyps in the gastrointestinal tract are shown in table 2 . There were both sessile and pedunculated polyps, and their size varied from $5 \mathrm{~mm}$ to $30 \mathrm{~mm}$. One child (infantile type) had polyps in the stomach and small intestine: gastric polyps (n $=2$ ) were removed by snare polypectomy, and small intestinal polyps (located in the terminal

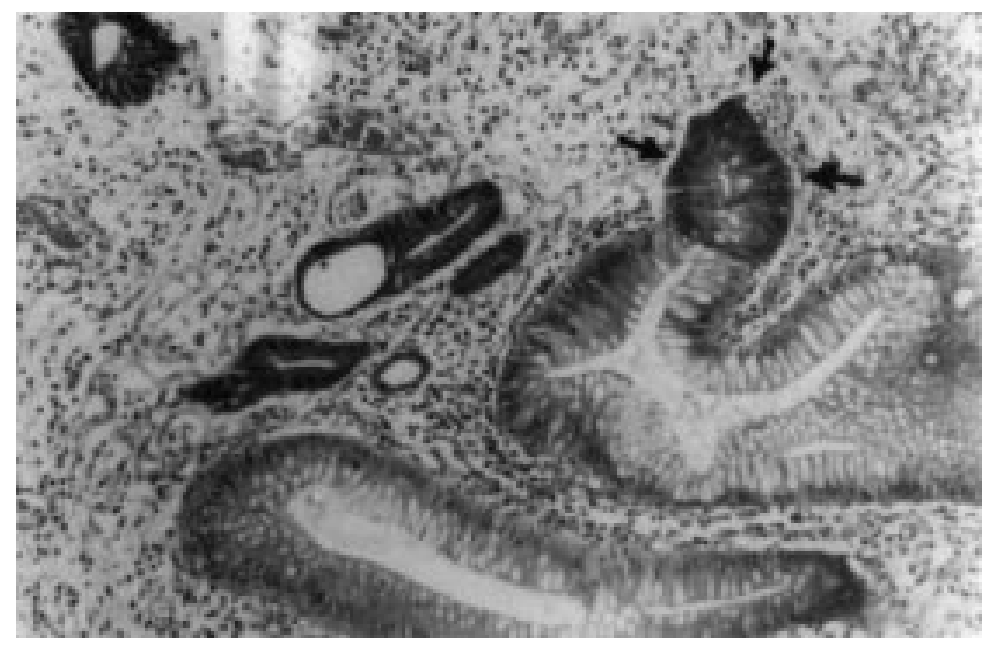

Figure 1 High power photomicrograph of a juvenile polyp with adenomatous changes (arrow) (haematoxylin and eosin, $\times 150$ ). ileum) were removed during surgery. On histology all 17 children had juvenile polyps. All polyps including polyps in the stomach and small intestine were "juvenile" in nature. Ten children (59\%) had juvenile polyps with adenomatous change (fig 1 ). In all such cases, the adenomatous changes were focal and low grade. The youngest child with adenomatous change was 3 years old. None had associated high grade dysplasia, adenoma, or carcinoma.

Colon clearance was achieved in eight children after serial polypectomy, three were still on the polypectomy programme at the time of writing, and six required surgery. The total number of polypectomy sessions was 77 , an average of 4.4 sessions per child. Children whose colons were cleared of polyps required an average of 3.4 sessions; the others went for surgery after 5.3 sessions, and were still on the polypectomy programme after 6.8 sessions. There were no major complications of polypectomy (bleeding or perforation). The surgery was done in five children because of intractable symptoms (bleeding, protein losing enteropathy, stunted growth) and in one for recurrent intussusception. The surgery comprised total colectomy, mucosal proctectomy, and ileoanal anastomosis. In one child the terminal ileum was also resected along with the colon.

In the early postoperative period all children had diarrhoea ( 15 to 20 stools per day) but over the next six months the stool frequency gradually diminished to seven per day. Otherwise the children were all doing well. The mean (SD) follow up was 28 (15) months (range 2.5 months to five years). On follow up, three of the eight children whose colons were cleared of polyps had recurrent polyps and these were again removed by colonoscopic polypectomy.

\section{Discussion}

Juvenile polyposis is a rare condition in children. There are three published series in English language journals. ${ }^{58}$ As a whole, familial polyposis (both adenomatous and hamartomatous) is uncommon in the Indian subcontinent compared to western countries. ${ }^{11}$ Family history, which is reported to be present in about one third of cases, ${ }^{12}$ was absent in our cases. This may be because inherited genetic changes responsible for colorectal neoplasia are uncommon in our race. Similarly we have not encountered any congenital anomaly. In fact, in the published reports many patients have no associated dysmorphic features, suggesting that there is genetic heterogeneity. ${ }^{13}$

Sachatello et al classified juvenile polyposis into three major clinical groups ${ }^{6}$ : juvenile polyposis of infancy, generalised juvenile polyposis, and juvenile polyposis of the colon. Juvenile polyposis of infancy presents before the age of 2 years with diarrhoea, haemorrhage, intussusception, rectal prolapse, and protein losing enteropathy. The entire gastrointestinal tract is usually affected, and the prognosis is poor without surgical intervention. One of our children had all the features of juvenile polyposis of infancy and he required surgery for intractable symptoms; the remainder had juvenile polyposis of the colon. A majority of these patients 
present in the second or third decade of life (though they may present as late as the sixth decade). ${ }^{57}$ This is the first report of a series where all the cases were children (up to 12 years of age). In previous studies, ${ }^{57}$ the mean age of presentation was 23, 27, and 34 years, compared with our 7.7 years.

Juvenile polyps are generally considered to be benign hamartomas. The risk of malignant change in a solitary juvenile polyp is small, ${ }^{14}{ }^{15}$ and a distinction must be made between these lesions and juvenile polyposis, where the risk is greater. Several reports have documented the presence of dysplastic changes representing a potential for malignancy. ${ }^{57}$ The dysplasia presents in two forms: coexistence of adenomatous changes in a juvenile polyp; and coexisting adenomas with no residual features of juvenile polyps. ${ }^{16}$ We found adenomatous change in 10 children in our study, but there was no associated pure adenoma or carcinoma in any of the polyps, even on resected specimens. Previous studies ${ }^{57}$ have shown adenomatous changes in $26-47 \%$, adenoma in $2-15 \%$, and carcinoma in $2.5-20 \%$ of cases of juvenile polyposis. The higher proportion of associated adenomatous change in our study may have been because we sent more polyps for histological examination, and some may have been atypical juvenile polyps (as described by Jass et $a l^{7}$ ). Our patients are younger ( $\leqslant 12$ years) than in other series, which may be the reason why we did not find any associated adenomas or carcinomas.

Is adenomatous change an indication for prophylactic colectomy? We think not, because these are focal and low grade dysplasias for which polypectomy is the usual treatment. ${ }^{5}$ Colonoscopic polypectomy followed by colonoscopic surveillance is a reasonable method of treatment, so long as polyp clearance is possible and patient compliance is good. ${ }^{17}$ Gilinsky et $a l^{18}$ employed serial colonoscopic polypectomy successfully in a patient aged 18 with juvenile polyposis despite the presence of adenomatous change with severe dysplasia; he was asymptomatic at follow up (after three years). There are insufficient data on juvenile polyposis to justify prophylactic colectomy solely because of the risk of colorectal carcinoma, ${ }^{5}$ as is done in adenomatous polyposis. However, colectomy should be carried out if there are intractable symptoms and stunted growth despite repeated polypec- tomy, if there is associated high grade dysplasia, when the colon cannot be cleared of polyps, or when compliance is poor. We employed sphincter preserving surgery (that is, mucosal proctectomy and ileoanal anastomosis), but because of the loss of colonic absorptive capacity, the children had greatly increased stool frequency at first-though with time the diarrhoea decreased, probably because of ileal adaptation. To minimise this problem, an ileal reservoir may be provided.

In conclusion, juvenile polyposis is not specially uncommon in Indian children. It is often associated with low grade dysplasia. Serial colonoscopic polypectomy is an effective method of treatment, but colectomy is required for intractable symptoms and when clearance of the colon is not possible.

1 Gelb A, Minkowitz S, Tresser M. Rectal and colonic polyps occurring in young people. $N Y$ State $\mathcal{F}$ Med 1962;62:513-8. 2 McColl I, Bussey HJR, Veale AM, et al. Juvenile polyposis coli. Proc R Soc Med 1964; 57: 896-7.

3 Veale AM, McColl I, Bussey HJ, et al. Juvenile polyposis coli. F Med Genet 1966;3:5-16.

4 Sachatello CR, Pickren JW, Grace JT. Generalised juvenile gastrointestinal polyposis: a hereditary syndrome. Gastroenterology 1970;58:699-708.

5 Giardiello FM, Hamilton SR, Kern SE, et al. Colorectal neoplasia in juvenile polyposis or juvenile polyps. Arch Dis neoplasia in juvenile p
Child 1991;66:971-5.

6 Sachatello CR, Hahn IS, Carrington CB. Juvenile gastrointestinal polyposis in a female infant: report of a case and review of the literature of a recently recognized syndrome. Surgery 1974;75:107-14

7 Jass JR, Williams CB, Bussey HJR, et al. Juvenile polyposis - a precancerous condition. Histopathology 1988; 13:619-30.

8 Bussey HJR. Familial polyposis. Baltimore: Johns Hopkins, 1975.

9 Thapa BR, Sahni A, Malik AK, et al. Juvenile polyposis coli: a management problem. Indian Pediatr 1990;27:863-6.

10 Jass JR, Sobin LH, eds. World Health Organisation: histological typing of intestinal tumours. 2nd Ed. New York: Springertyping of intestin.

11 Bhargava DK, Chopra P. Colorectal adenomas in a tropical country. Dis Colon Rectum 1988;31:692-3.

12 Smilow PC, Pryor CA, Swinton NW. Juvenile polyposis coli. A report of three patients in three generations. Dis Colon A report of three patien
Rectum $1966 ; 9: 248-54$.

13 Desai DC, Neale KF, Talbot IC, et al. Juvenile polyposis. $\mathrm{Br}$ f Surg 1995;82:14-17.

14 Liu TH, Chen MC, Tseng HC. Malignant change of a juvenile polyp of colon: a case report. Chin Med f 1978;4: 434-9.

15 Schilla FW. Carcinoma in a rectal polyp. Am f Surg 1954;88:759-60.

16 Goodman ZD, Yardley JH, Milligan FD. Pathogenesis of colonic polyps in multiple juvenile polyposis. Report of a case associated with gastric polyps and carcinoma of the rectum. Cancer 1979;43:1906-13.

17 Sturniolo GC, Montino MC, Dall'Igna F, et al. Familial juvenile polyposis coli: results of endoscopic treatment and juvenile polyposis coli: results of endoscopic treatment and 561-5.

18 Gilinsky NH, Elliot MS, Price SK, et al. The nutritional consequences and neoplastic potential of juvenile polyposis coli. Dis Colon Rectum 1986;29:417-20. 